\title{
A representação do tema drogas na mídia capixaba
}

Representation of the drugs theme in the media of the State of Espírito Santo

La representación del tema drogas en los medios de comunicación del Estado de Espírito Santo

\section{Eliana Martins Marcolino}

- Doutora em Comunicação Social pela Universidade Metodista de São Paulo Umesp), com estágio na Universidade de Havana (Cuba)

- Mestre em Comunicação Social pela Umesp

- Graduada em Jornalismo pelas Faculdades Integradas São Pedro (Faesa), de Vitória (ES)

- Pesquisadora do Observatório Saúde na Mídia (OSM) do Instituto de Comunicação e Informação Científica e Tecnológica em Saúde (Icict) da Fundação Oswaldo Cruz (Fiocruz)

- Experiência na área de comunicação, com ênfase em jornalismo e em comunicação e saúde

- E-mail: emarcolino@icict.fiocruz.br

\section{Edgard José Rebouças}

- Doutor em Comunicação Social pela Universidade Metodista de São Paulo (Umesp), com estágio de pesquisa na Université du Québec à Montréal

- Mestre em Sciences de IInformation et de la Communication pela Université de Grenoble 3

- Graduado em Jornalismo pela Universidade Federal do Espírito Santo (Ufes)

- Professor do Departamento de Comunicação Social da Ufes

- Coordenador do Observatório da Mídia Regional: Direitos Humanos, Políticas e Sistemas, da Ufes

- Experiência na área de comunicação, com ênfase em indústrias culturais e políticas

- E-mail: edreboucas.br@gmail.com 


\section{Resumo}

O presente trabalho refere-se à análise da cobertura do tema drogas em dois jornais da cidade de Vitória (ES): A Gazeta e A Tribuna. As matérias analisadas compreendem o período de $1^{\circ}$ a 31 de julho de 2010. Duas questões básicas constituem o problema de pesquisa: como os jornais capixabas abordam o tema; como o divulgam envolvendo crianças e adolescentes. Utilizou-se como método a análise de conteúdo das matérias e análise comparativa entre os jornais. Trata-se de um estudo exploratório documental, com enfoque qualitativo. A pesquisa mostra que o discurso que permeia os jornais capixabas em torno do tema drogas está centrado no modelo proibicionista e policialesco.

PALAVRAS-CHAVE: ADOLESCENTE • CRIANÇA • CIDADANIA • DROGAS • JORNALISMO

\section{Abstract}

This work concerns the analysis of the coverage of the drugs theme in two newspapers of the city of Vitória (ES): A Gazeta and A Tribuna. The subject-matters analyzed cover the period July 1 to 31, 2010. Two basic issues comprise the problem of the research: how the Espírito Santo newspapers address the theme; how do they divulge when it involves children and adolescents. The method used was an analysis of the content of the subject-matters and a comparative analysis between the newspapers. This concerns a documental exploratory study with a qualitative focus. The survey shows that the discussion that permeates the Espírito Santo newspapers in relation to the drugs theme is centered on the prohibitionist and police-like model.

KEYWORDS: ADOLESCENT • CHILD • CITIZENSHIP • DRUGS $\cdot$ JOURNALISM

\section{Resumen}

Este trabajo se refiere al análisis de la cobertura sobre la temática de las drogas en dos periódicos de la ciudad de Vitória (ES): A Gazeta y A Tribuna. Las materias analizadas comprenden el periodo de $1^{\circ}$ a 31 de julio de 2010. Dos cuestiones básicas constituyen el problema de investigación: cómo los periódicos del Estado de Espírito Santo abordan el tema y cómo lo divulgan envolviendo niños y adolescentes. Se utilizó como método el análisis de contenido de las materias y análisis comparativo entre los periódicos. Se trata de un estudio exploratorio documental, con enfoque cualitativo. La investigación muestra que el discurso que permea los periódicos del Estado de Espírito Santo en torno al tema de las drogas está centrado en el modelo prohibicionista y policialesco.

PALABRAS CLAVE: ADOLESCENTE • NIÑOS • CIUDADANÍA • DROGAS • PERIODISMO 

omo os jornais de maior circulação no estado do Espírito Santo - A Tribuna e A Gazeta² abordam o tema drogas? Esta é a pergunta que motivou o desenvolvimento da pesquisa. A questão central do estudo tem o objetivo de provocar uma reflexão sobre a cobertura do tema e as implicações do discurso legitimador da mídia na construção de um discurso social, considerando que a mídia detém um lugar privilegiado de fala.

A leitura cotidiana dos jornais forneceu um dado empírico importante para a escolha do tema: percebeu-se que ele vem ganhando cada vez mais a atenção da mídia, porém a maneira como os jornalistas tem falado sobre a temática merece um olhar crítico por parte dos leitores e dos produtores de conteúdos.

Este trabalho foi realizado no âmbito das atividades do Observatório da Mídia Regional: direitos humanos, políticas e sistemas, grupo de pesquisa e ação ligado à Universidade Federal do Espírito Santo, no qual se fomentam discussões sobre o papel social da mídia. No observatório, procura-se acompanhar como a mídia aborda questões de interesse público e se ela vem cumprindo o seu papel social de informar o público de maneira ética e responsável. Foi com o propósito de focar um olhar atento na construção do discurso da mídia sobre temas de interesse público que nos empenhamos no desenvolvimento desta pesquisa.

Nesse sentido, surgem os seguintes questionamentos: os jornais oferecem informações que possam contribuir com a análise crítica e reflexiva sobre o assunto, uma vez que a função do jornal é de informar e de formar opiniões? As matérias publicadas contribuem para que o leitor amplie 0 seu acervo de conhecimentos para tomadas de decisões? Em busca de respostas, adotou-se a abordagem metodológica da análise de conteúdo, tendo como expoentes teóricos deste estudo Laurence Bardin (2009) e Klauss Krippendorff (1993).

\section{Método de análise}

Segundo Krippendorff (1993), a análise de conteúdo é um procedimento de investigação sobre o significado simbólico das mensagens. Para Paul Lazarsfeld, citado por Bardin (2009, p. 20), trata-se de "uma técnica de investigação que tem por finalidade a descrição objetiva, sistemática e quantitativa do conteúdo, manifesto da comunicação". Para a realização desta pesquisa adotaram-se alguns procedimentos preconizados por Bardin, tais como: realizar a pré-análise dos textos, explorar o material, fazer o tratamento dos resultados e proceder à interpretação dos dados que foram elucidados.

\footnotetext{
1 Fundada em 22 de setembro de 1938.

${ }^{2}$ Fundada em 11 de setembro de 1928.
} 
Tão importante quanto a metodologia descrita por Bardin são os dez passos para a análise de conteúdo, apresentados por Kripendorff (1993). O primeiro é a formulação da hipótese ou questão para a pesquisa, sendo a hipótese uma pergunta que poderá ser confirmada ou refutada com a investigação. Após formular a questão de pesquisa, o segundo passo é definir a população para o estudo, ou seja, delimitar o material que será analisado dentro do universo de estudo. $O$ terceiro passo é selecionar uma amostra adequada, porque, dependendo do objeto de estudo, fica inviável analisar todo o universo, necessitando o pesquisador, portanto, lançar mão das técnicas de construção da amostragem. "A amostragem garante eficiência na pesquisa ao fornecer uma base lógica para o estudo de apenas parte de uma população sem que se percam as informações" (Bauer; Gaskell, 2002, p. 40).

O quarto passo é a seleção e definição das unidades de análise. Em um objeto de estudo, existem várias possibilidades de análise; logo, é necessário delimitar as unidades que serão avaliadas, como, por exemplo, analisar em um jornal apenas as propagandas ou somente as matérias jornalísticas do gênero informativo etc. A quinta etapa é a construção das categorias do conteúdo a ser analisado. As categorias precisam dar conta de responder aos questionamentos que se levantaram. Elas devem ser pertinentes aos objetivos do estudo e claramente formuladas, de modo a serem bem compreendidas pelos codificadores. Além disso, é importante evitar ambiguidades.

O sexto passo consiste em estabelecer um sistema de quantificação. Existem inúmeras possibilidades estatísticas para tratar os dados, o que vai depender do viés quantitativo e/ou qualitativo da pesquisa. O passo seguinte, o sétimo, diz respeito a treinar os codificadores e conduzir um estudo-piloto, que representa uma etapa muito importante para a validação do protocolo. É nessa fase que dúvidas são elucidadas e incongruências, eliminadas. Os codificadores devem ser orientados quanto ao preenchimento do protocolo para garantir maior uniformidade na leitura e interpretação das categorias de análise.

O oitavo passo é a codificação do conteúdo de acordo com as definições estabelecidas. A codificação correta do conteúdo é que vai definir o resultado da pesquisa. O nono passo se relaciona com a análise dos dados coletados, processo que envolve leitura crítica e visão holística acerca do tema estudado. Nessa fase é importante que o pesquisador se dispa de seus preconceitos e fique aberto para aceitar os resultados sem querer forçar a comprovação das hipóteses propostas, pois pode ser que o estudo refute as questões de pesquisa. E, por fim, o décimo e último passo: estabelecer conclusões e sugerir indicações. Além de levantar conclusões, a pesquisa, a partir dos dados empíricos evidenciados, deve apontar algumas recomendações.

Seguindo esses critérios, realizou-se um estudo exploratório documental, com base na análise de conteúdo categorial das matérias. Para tanto, realizou-se um estudo-piloto por meio de um grupo 
composto por nove estudantes do Curso de Especialização em Atenção Primária à Saúde, da Faculdade Católica do Espírito Santo os quais também atuam como profissionais de distintas áreas da saúde. Eles fizeram a leitura das matérias dos jornais em questão e preencheram questionários. Posteriormente, foi feita uma roda de discussão sobre o assunto, na qual os pontos divergentes ou que provocaram dúvidas eram avaliados para a equipe alcançar um consenso.

Também se realizou uma entrevista com a coordenadora da Casa de Liberdade Assistida Presença e Vida, de Vila Velha (ES), a pedagoga Maria Aparecida Guimarães, que, tendo lido e comentado todas as matérias, preencheu os questionários, dando ênfase às reportagens que envolviam crianças e adolescentes.

Foi elaborado um protocolo de análise composto por duas grandes categorias: uma administrativa e outra de conteúdo.

Quanto à categoria administrativa, destacaram-se: gêneros jornalísticos (informativo e opinativo). A classificação dos gêneros é um elemento importante para a compreensão das características do veículo que está sendo estudado. Conhecer o lugar de publicação de alguns temas, ou seja, as editorias, oferece subsídios para a interpretação de determinados conteúdos. Por exemplo, por que o tema drogas ocupa majoritariamente as páginas policiais? Por que determinados personagens (políticos, artistas, esportistas...), embora tenham cometido crimes, ocupam outras editorias que não as policiais? Podemos afirmar que o espaço reservado para algumas pessoas dentro de um jornal pode reforçar preconceitos ou privilégios existentes na sociedade. Ao ler o jornal, o leitor precisa conhecer a origem da informação, quem é o jornalista ou qual é a agência que produziu o conteúdo. Por isso é importante saber quando as matérias são assinadas ou não. Quanto à presença de ilustrações/explicações, os jornalistas utilizam distintos recursos de edição para facilitar a compreensão do conteúdo, como gráficos e infográficos, fotografias e desenhos utilizados para ilustrar os textos. Pode-se observar, em uma matéria, que determinadas pessoas são mais expostas em fotografias em comparação com outras. Portanto, a foto deve ser utilizada de forma cautelosa pelos jornalistas. É importante lembrar que deve haver proteção de crianças e adolescentes na exposição de suas imagens.

Na categoria de conteúdo, foi contemplado o quesito do caráter educativo do texto; Ao analisar o caráter educativo das matérias, pretende-se observar se o texto jornalístico "contribui para a formação do indivíduo ou para ampliar seu acervo de conhecimentos", conforme ressalta Samuel Pfrom Netto (1972, p. 38). Concordamos que o jornalismo deve contribuir para que o cidadão tenha elementos para uma leitura crítica acerca dos temas que denotem interesse social, partindo-se do princípio de que a informação pela informação não é suficiente. Por exemplo, o que pode mudar na vida de um cidadão com a informação de que "polícia apreendeu 402 kg de drogas"? 
Se essa informação não vier contextualizada, ela se torna vazia de sentido. As matérias jornalísticas precisam oferecer subsídios para que o cidadão pense sobre as implicações sociais e pessoais do assunto que é abordado na mídia.

Os descritores temáticos salientaram os temas relacionados à problemática proposta, que é a questão das drogas. Foram definidos os seguintes descritores: avanços médicos e tecnológicos; descobertas científicas; celebridades; corrupção; denúncia/apreensão; envolvimento de criança e do adolescente com drogas; lei de criação dos conselhos antidrogas; medicamentos; políticas públicas de tratamento da dependência das drogas; políticas de prevenção ao uso das drogas; políticas de fiscalização e punição; violência contra a criança e o adolescente; violência provocada por crianças e adolescentes. O objetivo era analisar como os jornais focaram as drogas como temática. Por exemplo, identificou-se que a questão das drogas lícitas quase não foi abordada nesse período de análise, embora existam dados científicos relacionando a violência intrafamiliar e a violência no trânsito ao uso de álcool. De acordo com estudo publicado na Revista Brasileira de Psiquiatria (Chalub; Telles, 2006), em $61,4 \%$ dos acidentes de trânsito foi detectada a presença de álcool nos exames dos envolvidos que não faleceram; em $52,9 \%$ dos casos fatais, as vitimas estavam alcoolizadas. Apesar disso, esse tema ficou à margem da discussão nos periódicos analisados.

Quanto às fontes consultadas, ao ler um jornal, o leitor precisa ficar atento a "quem fala". Quais são os sujeitos escolhidos pelo jornal para discorrer sobre determinada temática. Em um jornal pode-se perceber a preponderância de fontes oficiais em detrimento de outras vozes. Essas fontes podem ser representadas por pessoas ou instituições. Para contemplar esse quesito, foram elencadas as seguintes fontes: conselhos de direitos (tutelar, da criança e do adolescente, da assistência e de direitos humanos); cidadãos comuns/testemunhas; especialistas em direito; familiares dos usuários e dos traficantes; legisladores; ONGs/instituições; pesquisadores/cientistas; policiais/delegados; professores; psicólogos/psicanalistas/psiquiatras; religiosos; traficantes; usuários. Nesse item foi possível identificar quais são as vozes ecoadas pela mídia e qual é o discurso que elas constroem ou é legitimado pela mídia. Observe-se que o pluralismo de fontes é importante para garantir a expressão dos distintos discursos sobre a temática.

Sobre o tipo de droga mencionada, uma das preocupações desta pesquisa foi identificar quais são as drogas da contemporaneidade, segundo o discurso jornalístico. Ressaltamos que é segundo o discurso jornalístico, porque sabe-se que as drogas lícitas, como álcool e psicotrópicos, embora sejam muito utilizados, não estão visíveis nas páginas dos jornais. As respostas desse quesito foram: álcool, crack, cocaína, ecstasy, LSD, maconha, dentre outras.

No que se refere à abordagem do tema, os diferentes codificadores classificaram as matérias como: com profundidade, superficial, ética, reforçadora de preconceitos e de privilégios, sensa- 
cionalista. Destaque-se que as unidades de codificação são construídas de acordo com o escopo de pesquisa. Os resultados de cada categoria serão descritos a seguir.

\section{RESULTADOS E DISCUSSÃO}

A pesquisa resultou no total de 67 textos, sendo 35 de $A$ Gazeta e 32 de $A$ Tribuna. No jornal $A$ Gazeta, dentre os gêneros jornalísticos, o informativo foi o mais expressivo, com $60 \%$ de notícias. Também no jornal $A$ Tribuna o gênero informativo foi o mais representativo com $44 \%$, mas as reportagens foram maioria, sendo quatro delas reportagens especiais. Ao comparar esses dados, é importante observar que o jornal A Tribuna, que tem características mais populares, dedicou mais espaço ao tema investindo em reportagens. Na caracterização dos gêneros jornalísticos, a reportagem é um texto mais elaborado, mais amplo, que vai além do lide, enquanto a notícia se caracteriza por responder às perguntas essenciais do lide. É importante ressaltar que o tema foi expressivo em ambos os jornais em termos de quantidade de vezes em que ele foi citado, porém a abordagem e a profundidade do assunto foram questionáveis, conforme se pode observar na discussão a seguir.

No que se refere à disposição espacial das matérias, em $A$ Gazeta $51 \%$ delas estavam na editoria de Segurança e em A Tribuna 53\% apareceram na editoria de Polícia. Não obstante, também em A Gazeta o tema foi abordado por um viés policialesco, ou seja, o tema drogas foi visto como assunto de polícia; obviamente, não se pode negar que a problemática também seja de segurança pública, mas limitá-la a essa esfera é um equívoco, porque ela perpassa uma rede multifatorial que supera os limites das intervenções policiais.

No quesito de identificação dos autores, em A Gazeta, 53\% das matérias foram assinadas por jornalistas. Já no jornal $A$ Tribuna, $47 \%$ das matérias não foram assinadas e nem sequer consta a sua origem. Esse dado implica uma preocupação quanto ao modo de produção da notícia, uma vez que o jornal deve prezar pela credibilidade. Se não indicar ao leitor quem é o responsável pelo conteúdo, o veículo corre um sério risco de cair em descrédito. Nesse quesito, o jornal $A$ Gazeta é mais cauteloso, ao apresentar um número significativo de matérias assinadas por jornalistas, com o e-mail destes junto a seus nomes, abrindo mais um canal de diálogo direto entre a redação e o leitor.

Quanto à presença de ilustrações, as fotografias foram preponderantes em ambos os jornais. No jornal $A$ Gazeta, $54 \%$ dos textos não traziam ilustrações e $43 \%$ eram ilustradas com fotografias. No jornal A Tribuna, $68 \%$ das matérias foram ilustradas. Assim como A Gazeta, também A Tribuna utilizou a fotografia em maior escala como recurso iconográfico. Nesse tópico de ilustração das matérias, foi possível perceber algumas nuances importantes, como, por exemplo, uma reportagem publicada pelo jornal $A$ Gazeta, com o título "Personal trainer é preso por vender ecstasy 
e LSD" (Carraretto, 2010a, p. 8). A reportagem foi ilustrada com uma foto composta por drogas, dinheiro, computador e uma balança de precisão. No texto constavam apenas as iniciais do nome do personagem, mesmo que ele já tivesse 28 anos de idade, tendo a jornalista informado que a Polícia Federal havia divulgado apenas as inicias do suspeito. Foi no mínimo curioso observar que, no dia seguinte, outra reportagem publicada no mesmo jornal (Carraretto, 2010b, p. 11), pela mesma jornalista, relatava o episódio de uma jovem de 22 anos presa com $5 \mathrm{~kg}$ de crack na mochila da filha, trazia seu nome completo, além de fotos do rosto, da mochila e das drogas. Pergunta-se: seria mera coincidência o fato de o personal trainer ser morador de bairro nobre de Vitória e a mulher, uma desempregada residente de periferia? Esse fato permite questionar os critérios adotados pelos jornalistas para publicar ou não o nome de uma pessoa, para colocar ou não a foto dela. O que se percebe é que os jornais acabam por reproduzir os preconceitos existentes e também é sabido que ainda existem na corporação policial profissionais que tratam de maneira diferenciada as pessoas, de acordo com a sua classe social, e o que preocupa é que os jornalistas acabam reproduzindo e legitimando esse apartheid social.

Acerca do caráter educativo dos textos, em ambos os jornais $97 \%$ foram classificados como não-educativas. Em A Gazeta, 78\% foram classificados como superficiais, enquanto que na Tribuna o índice de $88 \%$. Esses dados merecem um olhar atento, visto que alguns questionamentos podem ser feitos sobre o que é considerado educativo. O que se classifica como superficial? Além disso, pode-se afirmar que também entra a subjetividade na análise de um texto. $E$ assim por diante. Tais questionamentos foram levantados pelos colaboradores na roda de discussão. Por isso, estabeleceu-se que, na leitura e avaliação das matérias, alguns pontos deviam ser considerados. Quanto ao caráter educativo, atentou-se para o que conceitua Pfrom Netto (1972, p. 38):

Quatro funções básicas têm sido convencionalmente atribuídas aos MCM: informar, divertir, persuadir e ensinar. A primeira diz respeito à difusão de notícias, relatos comentários etc. Sobre a realidade, acompanhada, ou não, de interpretações ou explicações. A segunda função atende à procura de distração, de evasão, de divertimento, por parte do público. Uma terceira função é persuadir o indivíduo - convencê-lo a adquirir certo produto, a votar em certo candidato, a se comportar de acordo com os desejos de um anunciante. A quarta função - ensinar - é realizada de modo indireto ou direto, intencional ou não, por meio de material que contribui para a formação do indivíduo ou para ampliar seu acervo de conhecimentos, planos, destreza etc.

Quanto à profundidade da notícia, observou-se a quantidade de fontes citadas, quais pessoas e instituições foram referenciadas, bem como a abrangência do tema. Por exemplo, os jornais denunciaram que, a cada dia, mais mulheres e crianças estão se tornando vítimas das drogas, como usuárias, como vendedoras e/ou como transportadoras do produto. A matéria que abordou a temática fez alguma alusão aos fatores socioculturais que podem contribuir para que esse público seja cada vez mais vulnerável? Ou seja, apresentou elementos complementares e não apenas as respostas às perguntas do lide clássico - O quê? Quem? Quando? Onde? Por quê? Como? 
Esses foram os critérios adotados para a análise dos textos quanto ao caráter educativo e à profundidade de abordagem do tema.

No que diz respeito aos descritores temáticos ou motes, em ambos os jornais o foco foi dado na denúncia e apreensão: o jornal $A$ Gazeta, com 56\%, e o jornal $A$ Tribuna, com 47\%. Esses dados também são preocupantes, uma vez que se sabe que o tema drogas abrange uma complexa discussão, que vai para além da segurança pública. Esse discurso que se constrói acaba por culminar em ações isoladas e porvezes equivocadas. Veem-se diariamente notícias sobre políticas de repressão ao tráfico que são realizadas a partir de parâmetros quantitativos, destacam-se a quantidade de pessoas envolvidas com o tráfico e consumo de drogas, o número de crianças cada vez mais pequeninas sendo vítimas, a quantidade de apreensão que são realizadas em um dia. Todos esses elementos devem ser acompanhados de sérias discussões, para as intervenções não serem feitas de maneira isolada. Espera-se que o jornalismo possa criar uma pedagogia a fim de que as pessoas, ao se informarem, tenham elementos para construir a sua opinião e fazer escolhas.

Cabe aqui mencionar uma metáfora do professor Apolo Heringer (2011) sobre o Rio das Velhas. Ele comparou algumas estratégias da saúde pública brasileira com um rio bem poluído, no qual os peixes estão todos adoecendo. Pesquisadores identificaram que um peixe está com problemas oftalmológicos. Para resolvê-los, fazem-se vultosos investimentos em cirurgia e tecnologia, para, no final, colocar óculos no peixe e o devolver para o mesmo rio poluído que o fez ficar doente. Ou seja, não basta fazer a intervenção isolada. Também é preciso, concomitantemente com a intervenção direta na saúde do peixe, despoluir o rio. Essa metáfora é bem pertinente diante das experiências fracassadas de determinadas políticas públicas, principalmente aquelas voltadas para a questão do combate ao consumo e tráfico de drogas. Isso tem revelado que não basta abrir clínicas de desintoxicação e internar as pessoas que têm dependência química. São necessárias ações conjuntas para evitar retirar a pessoa de um ambiente adoecedor, "recuperá-la" e posteriormente devolvê-la para o mesmo ambiente, o que não solucionaria o problema.

No caso dos menores em situação de risco, as instituições nas quais eles são internados, na maioria são espaços pouco acolhedores. Algumas se convertem em verdadeiras escolas da criminalidade, onde o garoto muitas vezes entra em uma condição e sai com alto nível de periculosidade. A fala de um entrevistado, identificado por Z, ao jornal $A$ Gazeta, na reportagem "O pesadelo da violência que chega ao interior" (Vogas, 2010) ilustra bem essa questão: "Faltam espaços socioeducativos. Não adianta trazer polícia para a cidade se não trouxerem emprego. Podem trazer um exército, mas, se não tiver trabalho, o sujeito vai roubar pra comer". Esse depoimento consta de uma reportagem sobre a chegada das drogas nas cidades interioranas do estado do Espírito Santo. Dessa mesma matéria cabe ressaltar a fala de Adamir de Oliveira presidente da associação de moradores da cidade de lbatiba (ES), "Onde falta infraestrutura, o tráfico se ins- 
tala" (apud Vogas, 2010). Com base nessas falas, é possível questionar as ações que o Estado tem adotado para promover a saúde e evitar que principalmente crianças e jovens sejam vítimas.

Sobre as fontes consultadas, no jornal $A$ Gazeta $65 \%$ são policiais, ou seja, são fontes oficiais da segurança pública. No jornal $A$ Tribuna, as fontes também são na maioria da corporação policial e $35 \%$ das matérias não fazem referência a fonte alguma. Esses dados se concatenam com a questão que pontuamos: a construção do discurso repressivo em torno de um tema que deve envolver a sociedade civil como um todo e, de modo especial, as instituições formadoras de opinião, como, escolas, universidades, instituições religiosas, grupos da sociedade civil organizada.

Na questão sobre os tipos de drogas mais mencionadas, no jornal A Gazeta são maconha, crack e cocaína, todas com $28 \%$ de referências. E no jornal A Tribuna a cocaína saiu na frente, com $41 \%$, seguida do crack, com $28 \%$. O que chama a atenção é que pouco se ouve falar sobre a questão do álcool e dos psicotrópicos, que são grandes causadores de problemas para a saúde pública no Brasil.

Na questão sobre os tipos de drogas mais mencionadas, no jornal $A$ Gazeta são maconha, crack e cocaína, todas com $28 \%$ de referências. E no jornal $A$ Tribuna a cocaína saiu na frente, com $41 \%$, seguida do crack, com $28 \%$. O que chama a atenção é que pouco se ouve falar sobre a questão do álcool e dos psicotrópicos, que são grandes causadores de problemas para a saúde pública no Brasil.

Sobre a abordagem do tema, em A Gazeta $10 \%$ dos textos versavam sobre o envolvimento de crianças e adolescentes com entorpecentes e $12 \%$ falavam da violência envolvendo menores, cifra que foi de $9 \%$ em $A$ Tribuna. Esses personagens foram retratados em algumas matérias, porém não como o assunto principal, aparecendo só em segundo plano. Destaca-se aqui a matéria "Vendas de drogas com bebê no colo" (A Tribuna, 2010). A reportagem dá conta de que um bebê de um mês e dois dias foi utilizado como escudo de um casal de namorados, do qual a mulher era uma adolescente de dezessete anos. O casal foi detido e o bebê, entregue à mãe, que era prima da adolescente.

Lia-se na reportagem "Tio e sobrinho assassinados em casa, na Fonte Grande" (A Gazeta, 2010a): "O desempregado José Pereira dos Santos Filho, 29 anos, e o sobrinho dele, o estudante Dênis dos Santos, 15, foram assassinados com tiros na cabeça, dentro de casa, na madrugada de ontem, no Morro da Fonte Grande, no Centro de Vitória”. A reportagem narrava com detalhes o ambiente do crime e descrevia o sofrimento da mãe do adolescente e da viúva, limitando-se ao drama fatídico.

A matéria "Adolescentes são presos por venda de drogas" (A Gazeta, 2010b) dizia: "Cinco adolescentes foram detidos pela Polícia Militar, na tarde de ontem, suspeitos de tráfico de drogas". Essa notícia tinha as características de um boletim de ocorrência da polícia, mostrando apenas o relato do fato sob a versão policial. 
"Adolescente é executado com 15 tiros na cabeça" (Rodrigues, 2010) era o título de matéria de A Tribuna sobre um adolescente, "identificado pela polícia apenas como Charlinho", morto "às 11 horas de ontem, no bairro Jardim Carapina, na Serra". O homicídio foi narrado como "uma tragédia a mais, mais um crime sem explicação, um pobre adolescente, ou um adolescente pobre, brutalmente assassinado, cujo corpo foi levado ao Departamento Médico Legal, onde aguarda o reconhecimento da família".

Em "Sexo, drogas e assaltos nos terminais do Transcol" (Celso Júnior, 2010), A Tribuna escrevia: "A falta de policiamento é apontada como um dos principais motivos da violência. Outras situações vistas por quem frequenta os terminais, são o tráfico de drogas e a prostituição. Há relatos de adolescentes que usam os terminais como ponto de encontro para programas sexuais com passageiros. Em dois dias percorrendo os terminais do Transcol, a reportagem de A Tribuna flagrou diversos crimes sendo praticados nos locais, como uso de drogas, tráfico e furtos praticados por crianças. Na tarde da última quarta-feira, por exemplo, no Terminal de Laranjeiras, na Serra, três crianças chamavam a atenção de comerciantes em meio a uma grande aglomeração de pessoas. Eram três meninas com idades entre 7 e 10 anos, já conhecidas no local por conta da prática de furtos. Elas agem sorrateiramente e levam mercadorias, aproveitando-se da distração dos vendedores. As meninas roubam e fogem a pé pelas vias laterais do terminal".

Diante da violência que é retratada nessa grande reportagem, a fala dos usuários está centrada no medo. Todos os entrevistados declararam sentir medo, enquanto que os comerciantes reclamam da falta de policiamento.

Os fragmentos citados servem para fomentar as reflexões acerca da temática. Diante do cenário apresentado se pode concluir que, ante a omissão do Estado, o tráfico se faz presente. Cada dia, mais crianças, adolescentes e mulheres estão sendo cooptadas pelo crime. A sociedade torna-se refém e panóptica. Assim, resta-nos responder a estas perguntas: o que fazer para enfrentar esses problemas? Como a mídia pode contribuir no enfrentamento dessas questões?

A experiência tem mostrado que apenas reprimir não é suficiente. Quanto às crianças e adolescentes, uma dura realidade foi revelada pela coordenadora da Casa de Liberdade Assistida Presença e Vida, Maria Aparecida Guimarães. Ela atestava que, apesar dos esforços das instituições para orientar os adolescentes envolvidos com drogas, o descaso do poder público é a maior barreira a ser enfrentada. O manejo desses adolescentes é permeado por jogo de interesse e pela discriminação. As penas não são aplicadas de acordo com a lei ou, melhor, a lei funciona apenas para os mais frágeis. As instituições públicas que deveriam oferecer retaguarda a esses menores os tratam com descaso, tornando esses ambientes pouco atrativos ou em alguns casos tão perigosos quanto um presídio comum. O que deveria ser um espaço socioeducativo torna-se uma "academia do crime".

Nesse contexto deveriam entrar os meios de comunicação, denunciando os abusos e controlando os três poderes. Ao perceber a fragilidade da mídia, a sociedade civil precisa entrar em ação 
como o "quinto poder", conforme preconiza Ignácio Ramonet (2003). O quinto poder deve nos permitir opor uma força cívica cidadã à nova coalizão dominante. Sua função seria denunciar o superpoder dos meios de comunicação, dos grandes grupos midiáticos, cúmplices e difusores da globalização liberal. Esses meios de comunicação que, muitas vezes deixam de defender os cidadãos, quando não atuam contra o povo em seu conjunto.

\section{CONSIDERAÇÕES FINAIS}

Acompanhar o trabalho da mídia é uma preocupação emergente, que vem se fortalecendo a cada dia com a criação dos observatórios de mídia, os quais são classificados como instâncias de supervisão midiática, vigiando a atividade dos meios de comunicação e atuando na sua revisão crítica.

Há quem diga que eles constituem uma espécie de quinto poder, aquele que se ocupa da fiscalização dos meios de comunicação e dos profissionais que ali atuam. Um novo contrapoder, já disse Ramonet (2003), capaz de oferecer uma 'arma coletiva' à sociedade nesses tempos de tirania da comunicação. Surgidos há poucos anos, os observatórios são instâncias de supervisão midiática que vigiam a atividade dos meios de comunicação. Mesmo que esta seja a sua função primeira, a versatilidade dessas instâncias tem permitido ampliar o repertório de suas atuações (Christofoletti; Herrera, 2006, p. 150).

Espera-se também que este estudo possa oferecer alguns elementos para fomentar na sociedade brasileira uma discussão sobre o tema drogas. Um dado importante é a compreensão de que as políticas públicas voltadas para o controle do tráfico e do consumo de entorpecentes devem ser analisadas sob perspectivas diversas. $O$ assunto merece ser apresentado e discutido nos ambientes acadêmicos e nas instâncias sociais.

O jornalismo tem um papel preponderante nesse contexto. Critica-se o jornalismo porque se acredita na sua potência. O discurso jornalístico tornar-se-á mais inteligente se for compartilhado com leitores críticos e inteligentes, que não aceitam as "verdades" como absolutas, mas passíveis de serem discutidas e questionadas. Cabe ao jornalismo uma importante função social. É por isso que ele não pode cair na banalização e ficar na mesmice do informar-por-informar, mas deve ser um grande provocador de debates que vão ao encontro das demandas sociais.

Um dado alentador diante desse cenário é que a saúde pública vem tratando da temática com a necessária seriedade.

No artigo "Modelos de atenção à saúde de usuários de álcool e outras drogas: discursos políticos, saberes e práticas", Vânia Alves (2009) afirma que, enquanto as políticas proibicionistas concentram esforços na redução da oferta e da demanda de drogas ilícitas, as políticas e os programas de redução de danos têm disseminado intervenções orientadas para a minimização dos danos à saúde, sociais e econômicos relacionados ao consumo de drogas sem a pretensão de coibi-lo. 
O foco deste estudo esteve centrado na preocupação de acompanhar a produção jornalística, para que a sociedade não seja alijada de seu direito de ser informada. Ela precisa participar do debate das políticas públicas para o enfrentamento de questões relacionadas com o consumo e o tráfico de substâncias psicoativas. Essas questões devem ser pensadas numa perspectiva da governança social.

Como vimos, não apenas no caso da cobertura de temas relacionados a drogas, mas sobretudo a elas, já passou o tempo de os jornalistas ficarem apenas presos às questões levantadas pelo lide ( $\mathrm{O}$ quê? Quem? Quando? Onde? Por quê? Como?). Elas, na verdade, não respondem a quase nada. Somente "mostram" e, em muitos casos, reproduzindo e perpetuando uma visão estereotipada dos problemas. Uma efetiva mudança no papel do jornalismo em relação às questões sociais só virá quando for incluída ao lide clássico uma sétima pergunta: e daí?

\section{REFERÊNCIAS}

A GAZETA. Tio e sobrinho assassinados em casa, na Fonte Grande. A Gazeta, Vitória (ES), 22 jul. 2010a.

Adolescentes são presos por venda de drogas. A Gazeta, Vitória (ES), 2010b.

ALVES, Vânia Sampaio. Modelos de atenção à saúde de usuários de álcool e outras drogas: discursos políticos, saberes e práticas. Cadernos de Saúde Pública, Rio de Janeiro, v. 25, n. 11, nov. 2009.

A TRIBUNA. Vendas de drogas com bebê no colo. A Tribuna, Vitória (ES), 16 jul. 2010.

BARDIN, Laurence. Análise de conteúdo. LLisboa, Portugal: Edições 70, 2009.

BAUER, Martin W.; GASKELL, George (Org.). Pesquisa qualitativa com texto, imagem e som: um manual prático. Petrópolis: Vozes, 2002.

CARRARETTO, Glaciere. Personal trainer é preso por vender ecstasy e LSD. A Gazeta, Vitória (ES), 06 jul. 2010 a. .Jovem é presa com 5 quilos de crack na mochila da filha. A Gazeta, Vitória (ES), 07 jul. $2010 b$.

CELSO JÚNIOR. Sexo, drogas e assaltos nos terminais do Transcol. A Tribuna, Vitória (ES), 26 jul. 2010.

CHALUB, Miguel; TELLES, Lisieux E. B. Álcool, drogas e crime. Revista Brasileira de Psiquiatria, São Paulo, v. 28, n. 2, out. 2006. Disponível em <http://dx.doi.org/10.1590/S1516-44462006000600004>. Acesso em: 15 fev. 2011.

CHRISTOFOLETTI, Rogério; HERRERA, Suzana. Topología de los observatorios de medios en Latinoamerica. Palabra Clave, v. 8, n. 2, p.153-174,2005. 
HERINGER, Apolo. Informação e comunicação em saúde. [Palestra]. Rio de Janeiro: Biblioteca da Fiocruz, 26 maio 2011.

KRIPPENDORFF, Klaus. Metodología de análisis de contenido: teoría y práctica. Barcelona: Paidós. 1993.

PFROM NETTO, Samuel. Comunicação de massa. São Paulo: Pioneira / Edusp, 1972.

RAMONET, Ignacio. Fiscalización ciudadana a los medios de comunicación: el quinto poder. Le Monde Diplomatique, Paris, out. 2003. Disponível em: <http://www.geocities.com/lospobresdelatierra2/altermedia/ramonet151003.html>. Acesso em: 15 fev. 2011.

RODRIGUES, Mylla. Adolescente é executado com 15 tiros na cabeça. A Tribuna, Vitória (ES), 18 jul. 2010.

VOGAS, Vitor. O pesadelo da violência que chega ao interior. A Gazeta, Vitória (ES), 26 jul. 2010.

Recebido em: 06.03.2012 / Aceito em: 19.04.2012 